\title{
Preliminary Results of Double-Bundle Anterior Cruciate Ligament Reconstruction and Technique-Specific Problems
}

\author{
Olcay Guler ${ }^{*}$, Ferdi Donmez ${ }^{2}$, Mahir Mahirogullari1, Mehmet Isyar'1, \\ Selami Cakmak ${ }^{3}$, Serhat Mutlu ${ }^{4}$ \\ ${ }^{1}$ Orthopedics and Traumatology Department, Medical Faculty, Medipol University, Istanbul, Turkey \\ ${ }^{2}$ Orthopedics and Traumatology Department, Yuzyil Hospital, Istanbul, Turkey \\ ${ }^{3}$ Orthopedics and Traumatology Department, Gulhane Military Medical Academy Haydarpasa Training Hospital, \\ Istanbul, Turkey \\ ${ }^{4}$ Orthopedics and Traumatology Department, Kanuni Sultan Suleyman Training Hospital, Istanbul, Turkey \\ Email: olcayguler77@gmail.com
}

Received 1 June 2014; revised 17 July 2014; accepted 31 July 2014

Copyright (C) 2014 by authors and Scientific Research Publishing Inc.

This work is licensed under the Creative Commons Attribution International License (CC BY). http://creativecommons.org/licenses/by/4.0/

\section{Open Access}

\section{Abstract}

Background: In this study, we determined the efficiency of anterior cruciate ligament (ACL) reconstruction using the double-bundle technique and addressed technique-specific problems. Patients and Methods: Twenty-nine patients who underwent ACL reconstruction due to ACL rupture with the arthroscopic double-bundle ENDOBUTTON CL method using autogenous hamstring tendons were evaluated. All patients were males and the mean age was 24.3 years (range 20 - 41 years). The mean follow-up period was 36.4 months (minimum 16 and maximum 53 months). Diagnosis was based on medical history and physical examination. Lachman, anterior drawer and pivot shift tests were performed. The patient diagnosis was verified with $\mathrm{X}$-ray roentgenogram and magnetic resonance imaging (MRI). Tunnel mergence and graft hanging problems were discussed. Results: Pre- and postoperative clinical assessments of the patients showed the mean Lysholm score increased from $60.2(48-72)$ preoperatively to $91.5(85-98)$ at the final visit, whereas the mean Tegner score increased from $5.58(3-9)$ preoperatively to $6.03(4-9)$ at the final visit. According to the International Knee Documentation Committee (IKDC) knee ligament standard evaluation system, five patients were classified as B (17\%); 11 patients were classified as C (38\%); and 13 patients were classified as $D(45 \%)$ before the surgery. At the postoperative evaluation, 17 (59\%) patients were classified as A; $11(38 \%)$ patients were classified as $B$; and $1(3 \%)$ patient was classified as $\mathrm{C}$. Conclusion: The double-bundle technique using hamstring tendons and femoral

${ }^{*}$ Corresponding author. 
braces is an efficient and satisfactory method for ACL reconstruction.

\author{
Keywords
}

ACL Reconstruction, Double-Bundle, Hamstring Tendon Graft, Femoral Brace

\title{
1. Introduction
}

The anterior cruciate ligament (ACL) is one of the most commonly injured ligaments in the knee [1]. ACL tears often lead to severe disabilities causing lifestyle changes [2]-[4]. In 1975, Girgis et al. reported for the first time that the ACL comprises two bundles [5], which are named for their relative anatomical insertion into the tibia [6]. Cadaveric studies have also revealed that the ACL comprises two bundles, anteriomedial (AM) and posterolateral (PL) [7]. The distinction between the two bundles is not based solely on anatomy. The AM and PL bundles have a synergistic but different function throughout the entire range of motion (ROM) of the knee [8]. In a fully extended knee, both the AM and PL are taut, with PL at its maximum. PL limits tibial rotation on the femur up to $60^{\circ}-90^{\circ}$ of knee flexion, after which PL loosens [9].

Since ACLs do not have appropriate healing potential, reconstructive surgery is suggested to prevent early degenerative changes, decrease the risk of reinjury and facilitate return to sporting activities [8].

Recent studies have focused on anatomical reconstruction of ACL ruptures and suggested more favorable clinical outcomes using the double-bundle technique. A bundle-specific ACL reconstruction can always be performed whether it is a single-bundle, double-bundle or augmentation procedure [10]. Although much of the evidence supports the use of the double-bundle technique [11], several trials have not found significant differences in clinical outcomes between the patient groups [6]. Although the double-bundle is similar to the single-bundle technique, several specific difficulties are associated with this method. In this study, we demonstrated the efficacy of the double-bundle technique together with anatomical ACL reconstruction, evaluated the clinical outcomes, and outlined the technical difficulties related to the double-bundle procedure and their management.

\section{Materials and Methods}

Twenty-nine patients diagnosed with an ACL rupture between January 2011 and June 2013 who underwent arthroscopic double-bundle ACL reconstruction with the Endobutton $\mathrm{Cl}$ using autogenous hamstring tendons were evaluated. The local Ethics Committee approved this study and all patients gave written informed consent. All patients were male. The mean age was 24.3 years (range 20 - 41 years). Mean knee flexion degree was 132, 4 (120 - 135) preoperatively. The right knee was affected in 18 (62\%) patients and the left knee in 11 (38\%) patients. The mean follow-up period was 36.4 months (minimum 16 and maximum 53 months; Table 1).

Diagnosis was based on medical history and physical examination. Lachman, anterior drawer, and pivot shift tests were performed. For each patient, diagnosis was verified with X-ray roentgenogram and magnetic resonance imaging (MRI). Functionality was assessed using the Lysholm scoring system, International Knee Documentation Committee (IKDC) knee ligament standard evaluation system, and Tegner activity score before the surgery and at the final visit. To confirm ACL tears, all patients underwent arthroscopic evaluation under general or regional anesthesia in the supine position under pneumatic tourniquet before the surgery. Accompanying pathologies were identified and appropriate treatments were performed.

A $4 \mathrm{~cm}$ longitudinal incision was made above the pes anserinus medial to the tuberositas tibia to reach the tendons of the gracilis and semitendinous muscles. Tendons were exposed using a tendon scraper (peeler) and attached muscle tissue was removed. The graft diameter was also determined. Soft tissue ACL residues on both the tibial and femoral sides were identified and labelled by an RF probe for anatomical ACL reconstruction. In chronic cases, soft tissue residues were not found, particularly on the femoral side. Therefore, we used the "resident ridge", the vertical bony tubercle located $4-8 \mathrm{~mm}$ in front of the lateral femoral cortex as a guide. Next, soft tissue located in the region that forms the upper border of the ACL insertion point was trimmed to obtain an adequate view.

The AM femoral tunnel was opened by anteromedial portal insertion at $100^{\circ}-110^{\circ}$ of knee flexion. The PL femoral tunnel was then opened in the area of the torn PL bundle footprint through an accessory anteromedial portal without guidance at $130^{\circ}$ of knee flexion. The knee was simultaneously maintained in a hyperflexed position to prevent peroneal nerve injury. To prevent tunnel mergence, a $2 \mathrm{~mm}$ bony bridge was maintained between the tunnels and axes of both divergent tunnels (Figure 1). Soft tissues in the notch and tibial footprint were re- 
Table 1. Patient profile and follow-up period.

\begin{tabular}{|c|c|c|c|c|c|}
\hline $\mathrm{S} / \mathrm{N}$ & Age & Gender & Postoperative follow-up duration (days) & Meniscal tear & Side \\
\hline 1 & 23 & M & 53 & Absent & $\mathrm{R}$ \\
\hline 2 & 21 & M & 49 & Absent & $\mathrm{L}$ \\
\hline 3 & 26 & M & 51 & Medial & $\mathrm{L}$ \\
\hline 4 & 22 & M & 41 & Absent & $\mathrm{R}$ \\
\hline 5 & 21 & M & 44 & Medial & $\mathrm{R}$ \\
\hline 6 & 23 & M & 39 & Lateral & $\mathrm{R}$ \\
\hline 7 & 21 & M & 47 & Absent & $\mathrm{L}$ \\
\hline 8 & 28 & M & 47 & Absent & $\mathrm{R}$ \\
\hline 9 & 24 & M & 55 & Absent & $\mathrm{R}$ \\
\hline 10 & 23 & M & 49 & Lateral & $\mathrm{L}$ \\
\hline 11 & 22 & M & 42 & Medial & $\mathrm{R}$ \\
\hline 12 & 26 & $\mathrm{M}$ & 43 & Absent & $\mathrm{L}$ \\
\hline 13 & 23 & $\mathrm{M}$ & 45 & Absent & $\mathrm{L}$ \\
\hline 14 & 22 & $\mathrm{M}$ & 45 & Absent & $\mathrm{R}$ \\
\hline 15 & 22 & $\mathrm{M}$ & 32 & Absent & $\mathrm{R}$ \\
\hline 16 & 20 & M & 31 & Absent & $\mathrm{R}$ \\
\hline 17 & 27 & M & 31 & Absent & $\mathrm{R}$ \\
\hline 18 & 20 & M & 31 & Absent & $\mathrm{L}$ \\
\hline 19 & 41 & M & 31 & Absent & $\mathrm{R}$ \\
\hline 20 & 20 & $\mathrm{M}$ & 30 & Absent & $\mathrm{L}$ \\
\hline 21 & 20 & $\mathrm{M}$ & 30 & Lateral & $\mathrm{L}$ \\
\hline 22 & 27 & M & 29 & Lateral & $\mathrm{R}$ \\
\hline 23 & 21 & $\mathrm{M}$ & 26 & Absent & $\mathrm{R}$ \\
\hline 24 & 23 & $\mathrm{M}$ & 26 & Absent & $\mathrm{L}$ \\
\hline 25 & 24 & $\mathrm{M}$ & 26 & Absent & $\mathrm{R}$ \\
\hline 26 & 36 & M & 23 & Absent & $\mathrm{L}$ \\
\hline 27 & 24 & $\mathrm{M}$ & 23 & Absent & $\mathrm{R}$ \\
\hline 28 & 25 & $\mathrm{M}$ & 20 & Absent & $\mathrm{R}$ \\
\hline 29 & 31 & M & 16 & Absent & $\mathrm{R}$ \\
\hline
\end{tabular}

moved to obtain a good view. To prevent mergence of femoral and tibial tunnels, various guiding devices provided by the Acufex Anatomic ACL Guide System (Memphis, TN, USA) and Knee Ligament Reconstruction Instruments (Arthrex, Inc., Naples, FL, USA) were used in some patients.

A tibial anteromedial skin incision was used when grafts were taken prior to tibial tunnel drilling. First, the tibial aimer was adjusted to $55^{\circ}$ and its tip was placed onto the anteromedial insertion point. A guidewire was deployed and the AM tibial tunnel was opened; the guidewire was left at this point. Next, the tibial aimer was adjusted to $45^{\circ}$ and its tip was placed onto the PL insertion point posterolaterally to the AM bundle. A guidewire was deployed and the PL tibial tunnel was opened. To prevent tunnel mergence, an $8 \mathrm{~mm}$ distance (a bony bridge) was maintained between the orifices of the two tunnels (Figure 2). The starting point of the PL tunnel was in the general vicinity of the tibial insertion point of the superficial medial collateral fibers above the tibia cortex, whereas the starting point of the anteromedial tunnel was between the PL tunnel and tibial tubercle. 


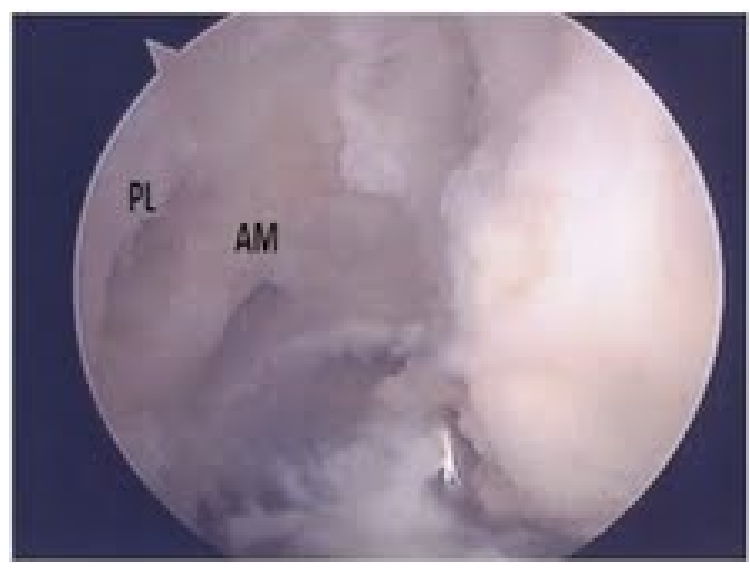

Figure 1. Arthroscopic view of the AM (anteriomedial) and PL (posterolateral) femoral tunnels at $100^{\circ}$ of knee flexion.

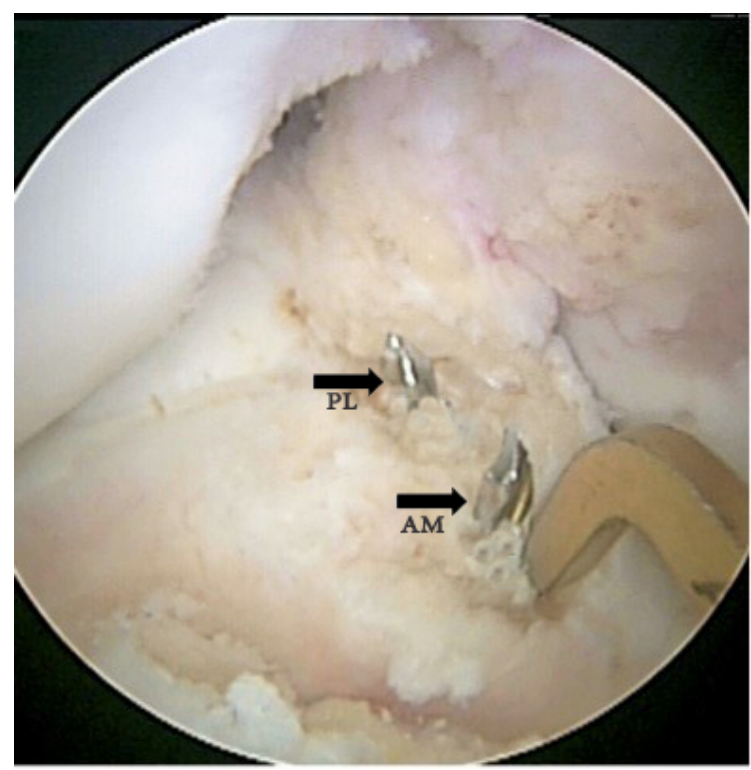

Figure 2. Insertion of tibial guidewires (size of image 72 $\times 72$ dpi).

The PL graft was placed first, followed by the AM graft. Fixation of the PL and AM grafts was achieved by an absorbable screw and an $\mathrm{U}$ nail at knee flexions of $0^{\circ}-15^{\circ}$ and $45^{\circ}-60^{\circ}$, respectively. Placement and tension of the grafts were controlled by arthroscopic imaging after fixation. In addition to the ACL rupture, seven patients had meniscal pathologies, which were treated during surgery. Three patients underwent arthroscopic partial menisectomy and in the other four cases, meniscus was repaired arthroscopically by vertical sutures using an inside-to-outside technique. On preoperative examination, the Endobutton attached to the PL tip moved up and remained in the muscle in two patients. The Endobutton was found from a $2 \mathrm{~cm}$ lateral incision and pushed down to the bone. The same condition was found postoperatively in two other patients who were then taken to the operating room. In one patient, PL fixation was removed and refixation was performed; in the other patient, the Endobutton was pushed down and the excess polyester fixation band was sutured using nonabsorbable material.

We encountered several problems related to the double-bundle technique including settling of the Endobutton through the muscle at lateral side, tunnel convergence and thin PL bundle.

We instructed patients to use angle-adjustable hinged knee braces for 3 weeks after surgery. Isometric quadricep exercises were started immediately following surgery. If a patient did not undergo meniscal repair or in- 
tervention to chondral lesions during reconstruction, permission was given for full weight bearing under control. Jogging was allowed at the end of months 3 and non-competitive sports after 6 months. After 9 months, patients were allowed to participate in any exercise of their choice.

The Statistical Package for the Social Sciences (SPSS) for Windows version 15.0 software was used for statistical analyses. In addition to descriptive statistics, (means and standard deviations), paired sample $t$-test and Wilcoxon matched-pairs signed-ranks test were used for qualitative data. Statistical significance was defined as a $p$-value $<0.05$ with a $95 \%$ confidence interval $(95 \% \mathrm{CI})$.

\section{Results}

Pre- and postoperative clinical assessments showed that the mean Lysholm score increased from 60.2 (48 - 72 ) preoperatively to 91.5 (85 - 98) at the final visit. The difference in Lysholm activity scores was statistically significant $(p<0.0001)$. The distribution of the Lysholm score is shown in Figure 3 and Table 3. Pre- and postoperative clinical evaluations showed that the mean Tegner score increased from $5.58(3-9)$ before surgery to $6.03(4-9)$ at the final visit. The difference in Tegner scores was statistically significant $(p=0.021)$. The distribution of Tegner scores is shown in Table 2 and Figure 4. According to the IKDC knee ligament standard eval-

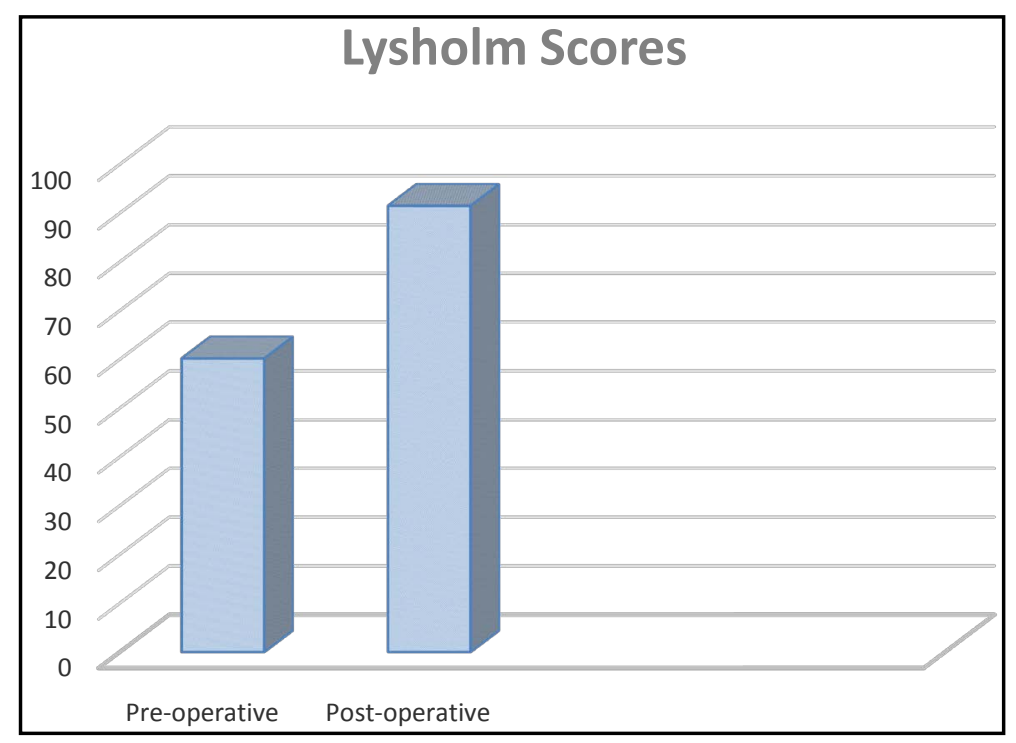

Figure 3. Preoperative and postoperative Lysholm scores. Schematic view of mean preoperative Lysholm (56.93) and post-operative (90.79) scores.

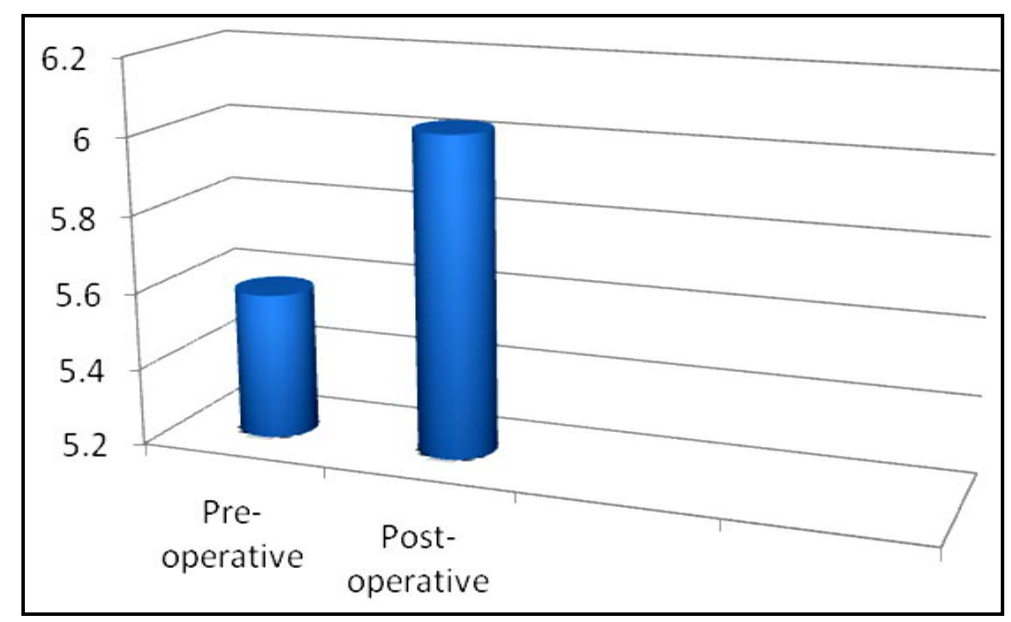

Figure 4. Preoperative and postoperative Tegner scores. 
Table 2. Preoperative and postoperative Lysholm and Tegner activity scores.

\begin{tabular}{|c|c|c|c|c|}
\hline \multirow{2}{*}{$\mathrm{S} / \mathrm{N}$} & \multicolumn{2}{|c|}{ Lysholm score } & \multicolumn{2}{|c|}{ Tegner activity score } \\
\hline & Preop & Postop & Preop & Postop \\
\hline 1 & 58 & 93 & 7 & 5 \\
\hline 2 & 54 & 95 & 6 & 6 \\
\hline 3 & 60 & 96 & 6 & 6 \\
\hline 4 & 54 & 88 & 5 & 3 \\
\hline 5 & 52 & 92 & 6 & 5 \\
\hline 6 & 72 & 95 & 7 & 5 \\
\hline 7 & 64 & 86 & 4 & 4 \\
\hline 8 & 48 & 86 & 6 & 5 \\
\hline 9 & 50 & 98 & 6 & 6 \\
\hline 10 & 53 & 94 & 7 & 6 \\
\hline 11 & 49 & 87 & 5 & 5 \\
\hline 12 & 53 & 90 & 7 & 7 \\
\hline 13 & 62 & 96 & 5 & 6 \\
\hline 14 & 57 & 92 & 8 & 6 \\
\hline 15 & 62 & 90 & 7 & 5 \\
\hline 16 & 60 & 90 & 6 & 5 \\
\hline 17 & 55 & 88 & 6 & 5 \\
\hline 18 & 60 & 96 & 9 & 9 \\
\hline 19 & 60 & 85 & 8 & 8 \\
\hline 20 & 53 & 88 & 5 & 5 \\
\hline 21 & 50 & 96 & 6 & 6 \\
\hline 22 & 53 & 85 & 5 & 6 \\
\hline 23 & 53 & 88 & 5 & 5 \\
\hline 24 & 60 & 90 & 6 & 5 \\
\hline 25 & 53 & 90 & 6 & 5 \\
\hline 26 & 60 & 90 & 7 & 7 \\
\hline 27 & 62 & 88 & 4 & 6 \\
\hline 28 & 60 & 87 & 5 & 5 \\
\hline 29 & 64 & 94 & 5 & 5 \\
\hline Mean value \pm Std. deviation & $56.93 \pm 5.5$ & $90.79 \pm 3.8$ & $6.03 \pm 1.17$ & $5.58 \pm 1.15$ \\
\hline p-value & $<0.05$ & & $<0.05$ & \\
\hline
\end{tabular}

uation system, 5 patients were classified as B (17\%), 11 as C (38\%) and 13 as D (45\%) before the surgery. At the postoperative evaluation, 17 (59\%) patients were classified as A, 11 (38\%) as B and $1(3 \%)$ as C. The difference in groups based on the IKDC knee ligament standard evaluation system was statistically significant $(p<$ 0.0001). The group distribution based on the IKDC knee ligament standard evaluation system is shown in Table 3.

\section{Discussion}

The indications for ACL surgery have been established [5] [6]. The indications for anatomical double-bundle 
Table 3. Preoperative and postoperative IKDC scores.

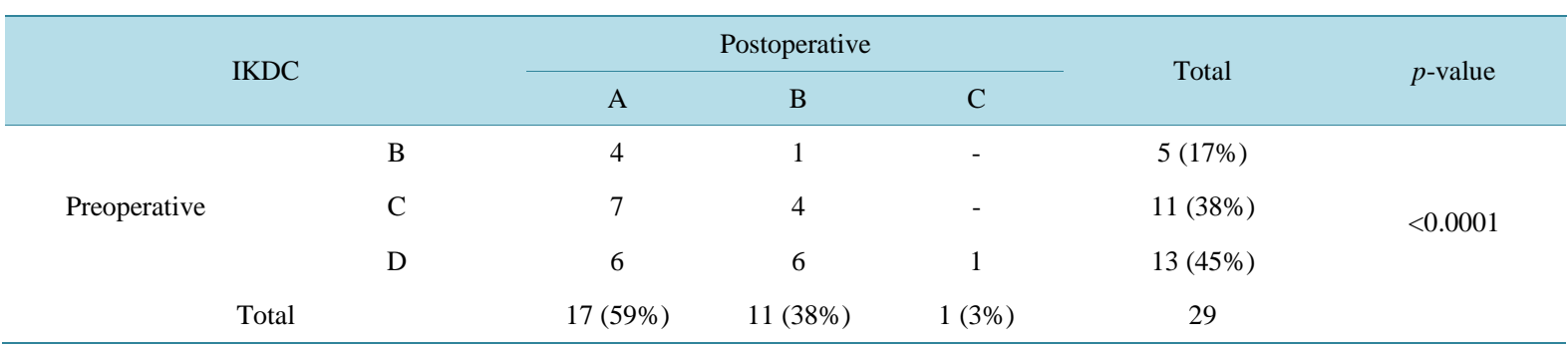

ACL reconstruction are similar to those for traditional single-bundle reconstruction.

The position of the femoral tunnel is an important parameter that may affect the outcome of the reconstruction surgery. This is important for both maintenance of proprioception (especially the tibial insertion point) and determining anatomical localization [12] [13] [20] [21]. Nagai et al. showed no significant distinction in sagittal and transverse planes between healthy and anatomically double-bundle ACL reconstructed knees in terms of TTDPM (sagittal and transverse plane threshold to detect passive motion) [14]. Traditional single-bundle reconstruction techniques most commonly result in a femoral high-AM tunnel position and extra-anatomical tunnel placements. In vitro studies demonstrated that nonanatomical single-bundle reconstructions could not be repaired with regard to normal anteroposterior or rotational instability. For ideal isometric graft placement, femoral tunnels should be $62 \%$ - $70 \%$ posterior to the Blumensaat line or anteroposterior diameter of the femoral sagittal plane [15]. The anatomical double-bundle reconstruction provides more space for the posterior wall compared to the single-bundle technique, allowing graft placement in a horizontal plane. Although several studies have reported that the risk of femoral condyle fracture is higher in double-tunnel reconstruction [16] [17], using biomechanical and computerized models, Smolinski et al. showed that the risk of fracture increased comparably in both methods [18]. To prevent merging, the femoral and tibial tunnels should be opened divergent rather than on the same axis, and soft tissues in the tibial footprint and notch should be removed to obtain a clear view. In our patients, no pathology was observed at early-midterm follow-ups; however, long-term outcomes should be monitored.

Hamstring tendons are the most commonly used grafts in double-tunnel reconstruction and were used in our patients. Gracilis and semitendinosus tendons were used as a double layer in all patients. However, the gracilis tendon for the PL bundle may be very thin $(\sim 5 \mathrm{~mm})$ in patients with autogenous grafting. Since the Endobutton drill is $4.5 \mathrm{~mm}$ in diameter, the graft may enter into the Endobutton tunnel if pulled with proximal force and the Endobutton could become stuck in the muscle like a kite. We used two approaches to prevent this condition in our patients, signing the femoral tunnel length and Endobutton somersault distance on the graft simultaneously while pulling slightly, or placing pliers at the level where the graft remained inside from the tibial tunnel orifice to the femoral tunnel roof. When the Endobutton was suspected to have formed a kite during the surgery, it was monitored via fluoroscopy. If the Endobutton was locked and stuck in the muscle, an incision was made in the skin proximally, the Endobutton sutures were tracked, the Endobutton was located within the muscle, released and pulled down. When this situation was observed after surgery, all implants were removed and replaced or the Endobutton was located proximally and slid onto the CL until the bone was strongly sutured from the long side using polyester sutures.

Anatomical and biomechanical studies on fetuses and cadavers verified that the ACL comprises two functional bundles with different dimensions and tension models. The results of these studies indicate the double-bundle technique regains better natural anatomy and knee kinematics compared to the single-bundle technique. Yasuda et al. reported in their cadaver study and case series that the use of hamstring tendons in double-bundle ACL reconstruction is effective for the surgical treatment of ACL injuries [19]. Kyung et al. reported that natural obliquity as well as almost normal knee kinematics is obtained after double-bundle reconstruction in the sagittal and coronal planes [20]. Yagi et al. showed in their cadaver study that better knee kinematic results are obtained with double-bundle reconstruction than with the single-bundle [21]. Yamazaki et al. demonstrated that only the tendon graft border is covered by collagen, as in the Sharpey fibers of the tunnel wall, in ACL reconstruction [22]. Delay et al. reported the central portion of the tendon graft remained necrotic 18 months after surgery in one patient [23]. Therefore, with regard to graft coverage and remodelling, we evaluate that double-bundle reconstruction would diminish necrotic central portion of tendon grafts and improve the coverage. 
Muneta et al. compared the double- and single-bundle ACL reconstruction results of 68 patients in a prospective randomized study [24]. They demonstrated improved results with the double-bundle method using a pivot shift, Lachman test and KT-1000 device. Yasuda et al. reported that ACL reconstruction using the anatomical double-bundle technique in 57 patients was satisfactory and safe [25]. Patients treated with double-bundle ACL reconstruction had increased AP knee stability according to KT-2000 measurements when compared to the single-bundle group [25]. Li et al. reported in their meta-analysis that double-bundle reconstruction was more successful than single-bundle in terms of diminishing rotational laxity [26]. The meta-analysis by Desai et al. showed primary AP stability and knee kinematics were better restored in anatomical double-bundle reconstruction than single-bundle [27]. Longo et al. stated the measurement systems are insufficient to evaluate rotational stability [28]. We used a pivot shift test to evaluate rotational stability during the follow-up period; the result was not positive in any patient. However, achieving relaxation to perform the pivot shift test in a patient who is not under anesthesia is difficult. Therefore, we agree with Longo et al. [28].

Zhu et al. reported better clinical outcomes with double-bundle ACL reconstruction than single-bundle [29]. The meta-analysis by Li et al. showed that double-bundle reconstruction diminishes graft insuffiency, is more successful than single-bundle in terms of knee joint stability and knee function, and recommended it as the primary treatment for ACL injuries [30]. Zaffagnini et al. reported that double-bundle reconstruction is better than single-bundle in terms of rotational control, functional scores and ROM [31]. Aglietti reported improved anterior stability and IKDC scores with the double-bundle technique [32]. In contrast, several studies have shown these techniques are similar. Adachi et al. conducted a randomized, prospective study in 108 patients and reported no significant difference between groups at the end of a 32-month follow-up period in terms of KT-2000 and joint position sense [33]. Suomalainen et al. reported after 5 years of follow-up, graft insufficiency and revision surgery occured less often with double-bundle reconstruction than single-bundle. In terms of knee stability and osteoarthritis, similar results are obtained with both techniques [34]. Ahlden et al. showed no significant differences between double-bundle and single-bundle reconstructions in the pivot shift test and objective as well as subjective conclusions after 2 years of follow-up [35]. Preliminary results may not show a difference in clinical outcomes, whereas long-term follow-up has demonstrated that the double-bundle technique prevents degeneration, indicating that long-term follow-up is necessary, which is one weakness of our study. Future studies should include a larger patient cohort with a longer follow-up period.

As reported in the literature, $30 \%-40 \%$ of patients experience knee symptoms after traditional single-bundle reconstruction and fail to return to their daily activities. Additionally, 90\% experience arthritic changes as early as 7 years after ACL reconstruction. Anatomical and biomechanical studies on fetuses and cadavers verified that ACL is comprised of two functional bundles with different dimensions and tension models. The results of these studies indicate that the double-bundle technique regains better natural anatomy and knee kinematics compared to the single-bundle technique. Several biomechanical studies have demonstrated that double-bundle ACL reconstruction results in better knee kinematics than single-bundle. Short-term and middle-term stages I and II randomized clinical trials showed promising results for this technique. Objective parameters indicate that doublebundle ACL reconstruction results in increased stability [13].

We suggest that surgery should be performed if young and active patients feel knee instability in their daily life and sporting activities. In patients with an ACL rupture, the goal is to achieve an activity level similar or close to that pre-trauma, otherwise the patient will likely have to adjust their activity level.

\section{Conclusion}

In conclusion, the double-bundle technique is a successful treatment method for ACL injury. Problems related to this technique can be minimized and this treatment method can be performed as a classical ACL reconstruction technique.

\section{Conflicts of Interest Disclosure}

Authors declared no conflicts of interests.

\section{References}

[1] Gianotti, S.M., Marshall, S.W., Hume, P.A. and Bunt, L. (2009) Incidence of Anterior Cruciate Ligament Injury and 
Other Knee Ligament Injuries: Anational Population-Based Study. Journal of Science and Medicine in Sport, 12, 622-627. http://dx.doi.org/10.1016/j.jsams.2008.07.005

[2] Harner, C.D., Fu, F.H., Irrgang, J.J. and Vogrin, T.M. (2001) Anterior and Posterior Cruciate Ligament Reconstruction in the New Millennium: A Global Perspective. Knee Surgery, Sports Traumatology, Arthroscopy, 9, 330-336. http://dx.doi.org/10.1007/s001670100230

[3] Maletius, W. and Messner, K. (1999) Eighteen- to Twenty-Four-Year Follow-Up after Complete Rupture of the Anterior Cruciate Ligament. The American Journal of Sports Medicine, 27, 711-717.

[4] Heijink, A., Gomoll, A.H., Madry, H., Drobnič, M., Filardo, G., Espregueira-Mendes, J. and Van Dijk, C.N. (2012) Biomechanical Considerations in the Pathogenesis of Osteoarthritis of the Knee. Knee Surgery, Sports Traumatology, Arthroscopy, 20, 423-435. http://dx.doi.org/10.1007/s00167-011-1818-0

[5] Girgis, F.G., Marshall, J.L. and Monajem, A. (1975) The Cruciate Ligament Soft the Knee Joint. Anatomical, Functional and Experimental Analysis. Clinical Orthopaedics and Related Research, Issue 106, 216-231. http://dx.doi.org/10.1097/00003086-197501000-00033

[6] Arnoczky, S.P. (1983) Anatomy of the Anterior Cruciate Ligament. Clinical Orthopaedics and Related Research, 172, 19-25.

[7] Schreiber, V.M., van Eck, C.F. and Fu, F.H. (2010) Anatomic Double-Bundle ACL Reconstruction. Sports Medicine and Arthroscopy Review, 18, 27-32.

[8] Muller, B., Hofbauer, M., Wongcharoenwatana, J. and Fu, F.H. (2013) Indications and Contraindications. For DoubleBundle ACL Reconstruction. International Orthopaedics (SICOT), 37, 239-246. http://dx.doi.org/10.1007/s00264-012-1683-6

[9] Gabriel, M.T., Wong, E.K., Woo, S.L.-Y., Yagi. M. and Debski, R.E. (2004) Distribution of in Situ Forces in the Anterior Cruciate Ligament in Response to Rotatory Loads. Journal of Orthopaedic Research, 22, 85-89. http://dx.doi.org/10.1016/S0736-0266(03)00133-5

[10] Van Eck, C.F., Lesniak, B.P., Schreiber, V.M. and Fu, F.H. (2010) Anatomic Single- and Double-Bundle Anterior Cruciate Ligament Reconstruction Flow Chart. Arthroscopy, 26, 258-268. http://dx.doi.org/10.1016/j.arthro.2009.07.027

[11] Amis, A.A. and Dawkins, G.P. (1991) Functional Anatomy of the Anterior Cruciate Ligament. Fibre Bundle Actions Related to Ligament Replacements and Injuries. Journal of Bone and Joint Surgery. British Volume, 73, $260-267$.

[12] Fu, F.H., Benett, C.H., Ma, C.B., Menetrey, J. and Lattermann, C. (2000) Current Concepts, Current Trends in Anterior Cruciate Ligament Reconstruction Part 2, Operative Procedures and Clinical. American Journal of Sports Medicine, 28, 124-130.

[13] Lattermann, C., Zelle, B.A., Ferretti, M., Chabara, A. and Fu, F.H. (2005) Anatomic Double-Bundle Anterior Cruciate Ligament Reconstruction. Techniques in Orthopaedics, 20, 414-420.

[14] Nagai, T., Heebner, N.R., Sell, T.C., Nakagawa, T., Fu, F.H. and Lephart, S.M. (2013) Restoration of Sagittal and Transverse Plane Proprioception Following Anatomic Double-Bundle ACL Reconstruction. Knee Surgery, Sports Traumatology, Arthroscopy, 21, 2048-2056. http://dx.doi.org/10.1007/s00167-012-2188-y

[15] Cohen, S.B., Starman, J.S. and Fu, F.H. (2006) Anatomical Double-Bundle Anterior Cruciate Ligament Reconstruction. Techniques in Knee Surgery, 5, 99-106. http://dx.doi.org/10.1097/00132588-200606000-00007

[16] Han, Y., Sardar, Z., McGrail, S., Steffen, T. and Martineau, P.A. (2011) Peri-Anterior Cruciate Ligament Reconstruction Femur Fracture: A Biomechanical Analysis of the Femoral Tunnel as a Stress Riser. Knee Surgery, Sports Traumatology, Arthroscopy, 19, S77-S85.

[17] Wiley, W.B., Owen, J.R., Pearson, S.E., Wayne, J.S. and Goradia, V.K. (2007) Medial Femoral Condyle Strength after Tunnel Placement for Single- and Double-Bundle Posterior Cruciate Ligament Reconstruction. Journal of Knee Surgery, 20, 223-227.

[18] Smolinski, P., O’Farrell, M., Bell, K., Gilbertson, L. and Fu, F.H. (2012) Effect of ACL Reconstruction Tunnels on Stress in the Distal Femur. Knee Surgery, Sports Traumatology, Arthroscopy, 21, 839-845.

[19] Yasuda, K., Kondo, E., Ichiyama, H., Kitamura, N., Tanabe, Y., Tohyama, H. and Minami, A. (2004) Anatomic Reconstruction of the Anteromedial and Posterolateral Bundles of the Anterior Cruciate Ligament Using Hamstring Tendon Grafts. Arthroscopy, 20, 1015-1025. http://dx.doi.org/10.1016/j.arthro.2004.08.010

[20] Kyong, B.S., Kim, J.G., Chang, M., Jang, K.M., Lee, S.S., Ahn, J.H. and Wang, J.H. (2013) Anatomic Double-Bundle Reconstruction Techniques Result in Graft Obliquities that Closely Mimic the Native Anterior Cruciate Ligament Anatomy. American Journal of Sports Medicine, 41, 1302-1309. http://dx.doi.org/10.1177/0363546513484692

[21] Yagi, M., Wong, E.K., Kanamori, A., Debski, R.E., Fu, F.H. and Woo, S.L. (2002) Biomechanical Analysis of an Anatomic Anterior Cruciate Ligament Reconstruction. American Journal of Sports Medicine, 30, 660-666. 
[22] Yamazaki, S., Yasuda, K., Tomita, F., Minami, A. and Tohyama, H. (2002) The Effect of Graft-Tunnel Diameter Disparity on Intraosseous Healing of the Flexor Tendon Graft in Anterior Cruciate Ligament Reconstruction. American Journal of Sports Medicine, 30, 498-505.

[23] Delay, B.S., McGrath, B.E. and Mindell, E.R. (2002) Observations on a Retrieved Patellar Tendon Autograft Used to Reconstruct the Anterior Cruciate Ligament: A Case Report. Journal of Bone \& Joint Surgery-American Volume, 84, 1433-1438.

[24] Muneta, T., Sekiya, I., Yagishita, K., Ju, Y.J., Hara, K., Nimura, A., Yagishita, K. and Sekiya, I. (2007) A Prospective Randomized Study of 4-Strand Semitendinosus Tendon Anterior Cruciate Ligament Reconstruction Comparing SingleBundle and Double-Bundle Techniques. Arthroscopy: The Journal of Arthroscopic and Related Surgery, 23, 618-628. http://dx.doi.org/10.1016/j.arthro.2007.04.010

[25] Yasuda, K., van Eck, C.F., Hoshino, Y., Fu, F.H. and Tashman, S. (2011) Anatomic Single- and Double-Bundle Anterior Cruciate Ligament Reconstruction, Part 1: Basic Science. American Journal of Sports Medicine, 39, 1789-1799.

[26] Li, Y.L., Ning, G.Z., Wu, Q., Wu, Q.L., Li, Y., Hao, Y. and Feng, S.Q. (2014) Single-Bundle or Double-Bundle for Anterior Cruciate Ligament Reconstruction: A Meta-Analysis. The Knee, 21, 28-37. http://dx.doi.org/10.1016/j.knee.2012.12.004

[27] Desai, N., Bjornsson, H., Musahl, V., Bhandari, M., Petzold, M., Fu, F.H. and Samuelsson, K. (2013) Anatomic Single- versus Double-Bundle ACL Reconstruction: A Meta-Analysis. Knee Surgery, Sports Traumatology, Arthroscopy, 22, 1009-1023.

[28] Longo, U., King, B., Denaro, V. and Maffull, N. (2008) Double-Bundle Arthroscopic Reconstruction of the Anterior Cruciate Ligament. Journal of Bone \& Joint Surgery, 90, 995-999.

[29] Zhu, Y., Tang, R., Zhao, P., Zhu, S.S., Li, Y.G. and Li, J.B. (2013) Double-Bundle Reconstruction Results in Superior Clinical Outcome than Single-Bundle Reconstruction. Knee Surgery, Sports Traumatology, Arthroscopy, 21, 10851096. http://dx.doi.org/10.1007/s00167-012-2073-8

[30] Li, X., Xu, C., Song, J., Jiang, N. and Yu, B. (2013) Single-Bundle versus Double-Bundle Anterior Cruciate Ligament Reconstruction: An Up-to-Date Meta-Analysis. International Orthopaedics, 37, 213-226. http://dx.doi.org/10.1007/s00264-012-1651-1

[31] Zaffagnini, S., Bruni, D., Marcheggiani Muccioli, G.M., Bonanzinga, T., Lopomo, N., Bignozzi, S. and Marcacci, M. (2011) Single-Bundle Patellar Tendon versus Non-Anatomical Double-Bundle Hamstrings ACL Reconstruction: A Prospective Randomized Study at 8-Year Minimum Follow-Up. Knee Surgery, Sports Traumatology, Arthroscopy, 19, 390-397. http://dx.doi.org/10.1007/s00167-010-1225-y

[32] Aglietti, P., Giron, F., Losco, M., Cuomo, P., Ciardullo, A. and Mondanelli, N. (2010) Comparison between Singleand Double-Bundle Anterior Cruciate Ligament Reconstruction: A Prospective, Randomized, Single-Blinded Clinical Trial. American Journal of Sports Medicine, 38, 25-34. http://dx.doi.org/10.1177/0363546509347096

[33] Adachi, N., Ochi, M., Uchio, Y., Iwasa, J., Kuriwaka, M. and Ito, Y. (2004) Reconstruction of the Anterior Cruciate Ligament. Single- versus Double-Bundle Multi-Stranded Hamstring Tendons. Journal of Bone and Joint Surgery. British Volume, 86, 515-520.

[34] Suomalainen, P., Järvelä, T., Paakkala, A., Kannus, P. and Järvinen, M. (2012) Double-Bundle versus Single-Bundle Anterior Cruciate Ligament Reconstruction: A Prospective Randomized Study with 5-Year Results. American Journal of Sports Medicine, 40, 1511-1518.

[35] Ahldén, M., Sernert, N., Karlsson, J. and Kartus, J. (2013) A Prospective Randomized Study Comparing Double- and Single-Bundle Techniques for Anterior Cruciate Ligament Reconstruction. American Journal of Sports Medicine, 41, 2484-2491. 
Scientific Research Publishing (SCIRP) is one of the largest Open Access journal publishers. It is currently publishing more than 200 open access, online, peer-reviewed journals covering a wide range of academic disciplines. SCIRP serves the worldwide academic communities and contributes to the progress and application of science with its publication.

Other selected journals from SCIRP are listed as below. Submit your manuscript to us via either submit@scirp.org or Online Submission Portal.
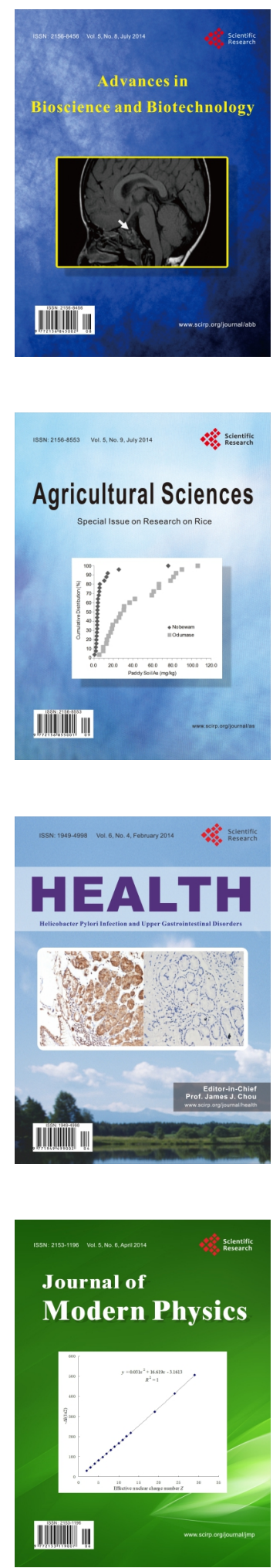
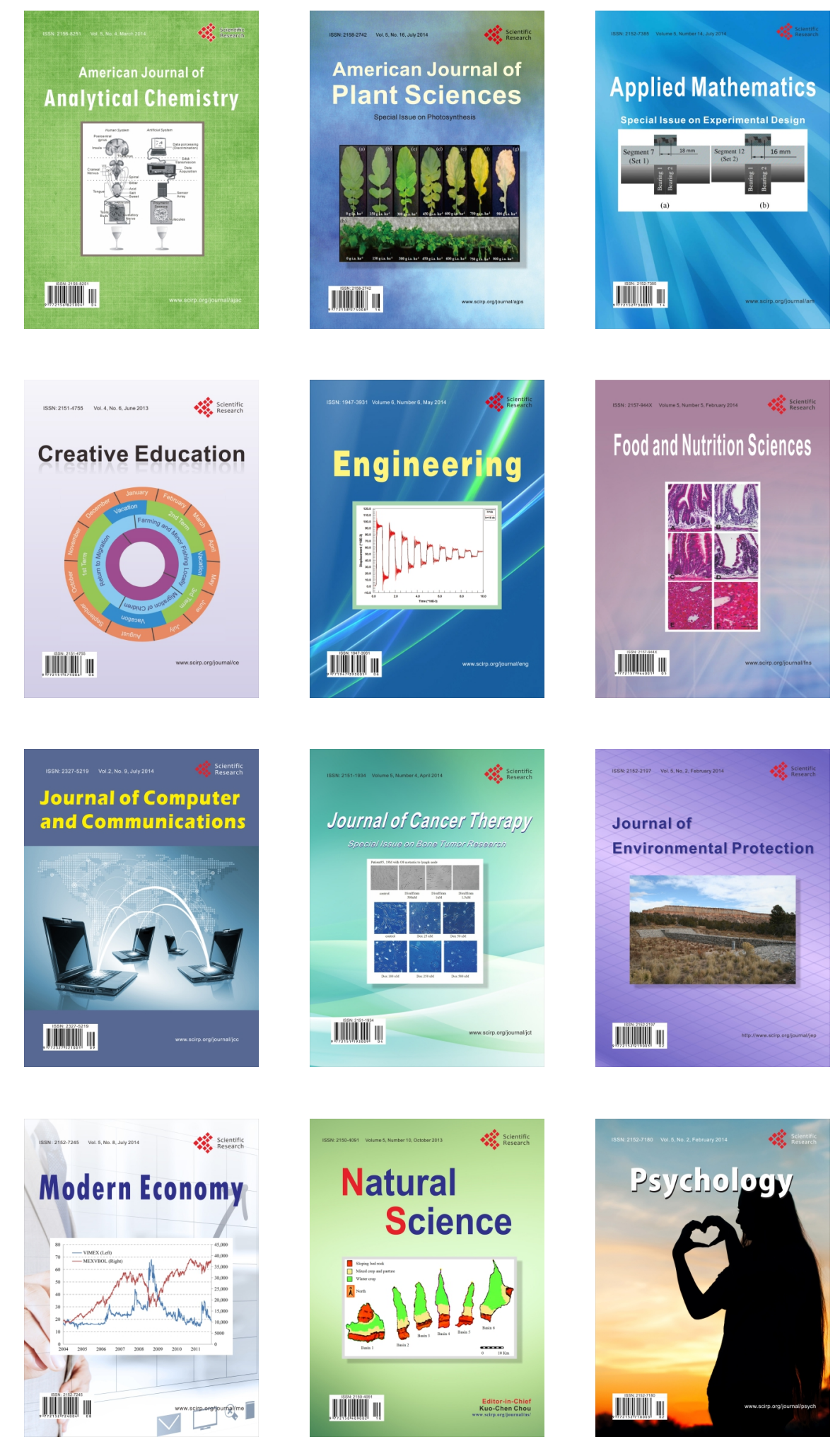